\title{
THE ANABOLIC EFFECTS OF CHORIONIC GONADOTROPIN IN NORMAL YOUNG MEN 1, 2, 3
}

\section{BY RICHARD L. LANDAU, KATHRYN KNOWLTON, KATHLEEN LUGIBIHL, MINNIE BRANDT, AND ALLAN T. KENYON \\ (From The Department of Medicine of the University of Chicago)}

(Submitted for publication December 5, 1949; accepted, January 23, 1950)

It is now possible to ascribe an anabolic effect to the testicular secretion involving the deposition of protein and bone salts in somatic structures $(1,2)$. Such processes may be interpreted as contributing to the physiological spurts in height and weight during puberty and adolescence (1). As growth ceases and the youth moves toward the nitrogen equilibrium of maturity the influences of anabolic forces that operated clearly enough during active growth become uncertain. It may be presumed that the amounts of testicular secretion necessary to maintain the functions of the genitalia are no longer sufficient to exert progressive anabolic force elsewhere. Yet there is no indication that the capacity of somatic tissues to respond to androgens has reached its uttermost limit with the assumption of adult life. The anabolic effects of testosterone propionate may be well demonstrated to some degree and for a while in normal young men $(3,4)$ and even in advanced age (5). A multiplicity of subjects of all ages and with a variety of diseases have been found sensitive to testosterone propionate. Although the clinical circumstances have been too numerous and too complex for treatment here, ample evidence exists that serious resistance to the anabolic effects of the androgens must be rare indeed.

The question now arises as to whether the secretory capacity of the mature testis is ever suf-

\footnotetext{
1 Read at the Fortieth Annual Meeting of the American Society for Clinical Investigation, May 3, 1948, and at the Thirtieth Annual Meeting of the Association for the Study of Internal Secretions, June 18 and 19, 1948.

2 This work was supported by a grant from the American Cancer Society on recommendation by the Committee on Growth. It was also aided by a grant from the Douglas Smith Foundation for Medical Research (R. L. Landau).

3 We are indebted to Ayerst, McKenna and Harrison (E. C. Reifenstein, Jr.) and to Squibb and Sons (Robert Bates) for the chorionic gonadotropin, and to the Schering Corp. (E. Henderson) for the testosterone propionate used in these studies.
}

ficient to take full advantage of this peripheral sensitivity to androgens. The limitation on anabolic processes with the advent of maturity may lie in part in physiological inertia of the testis to pituitary stimulation or in a moderated delivery of gonadotropin to a fully responsive testis. This matter is of considerable importance in any analysis of the control of protein metabolism during adult life. A testis sensitive to increments in pituitary stimuli above the normal maintenance level could contribute to the support of appropriate anabolic processes as occasion arises. No account of such testicular participation in the regulation of physiological variations in protein metabolism during adult life has thus far been possible.

The capacity of the testis of the normal young adult to respond to suitable stimuli has been studied in four subjects reported here, using the familiar metabolic indicators of androgen production. Interstitial cell stimulating material of pituitary origin being unavailable chorionic gonadotropin has been used. Previous work of our own has shown this material to produce retention of nitrogen, inorganic phosphorus, sulfate and creatine in a manner similar to testosterone propionate in a short boy in early puberty (6). In an attempt to exclude any direct effects of chorionic material on somatic tissues and any intervention of another gland, such as the adrenal cortex, a comparative study was made on a eunuchoid with presumably inactive testes. No youthful castrate was available.

In preliminary studies not dealt with here, 250750 I.U. of chorionic gonadotropin per day were given for three days to each of several normal young men (7). Slight to moderate declines in the excretion of urinary nitrogen and inorganic phosphorus as well as substantial elevations in urinary 17-ketosteroids were induced. Unfortunately, febrile reactions and local inflammation oc- 
curred, complicating the interpretation of the data. In the present studies a more highly purified preparation was so well borne that $1,000-3,000$ I.U. daily could be given without reaction. We thus believe that the results reported here are due to chorionic material itself, unaffected by toxic contaminants. Studies on the composition of the 17 -ketosteroid mixtures ( 8 ) to be reported in detail later support this opinion. A peculiarity of the response seen after adrenocorticotropin, one that might have been expected in a toxic reaction, did not occur after chorionic material. The nature of this distinctive element in response will be briefly described in the discussion.

\section{METHODS}

Four of the subjects were physically healthy student volunteers. One (Y. W.) was a eunuchoid. They lived in the hospital for the duration of the studies pursuing their accustomed work as students. Physical activity did not vary greatly from day to day. A constant diet was fed throughout, metabolic changes being detected largely by variations in urinary excretion. Twenty-four hour urine collections were made and analyzed either as single specimens or two day pools. The manner of conducting the metabolic experiments and the chemical methods for the determination of urinary nitrogen, inorganic phosphorus, creatine, creatinine, chloride and potassium and of blood constituents have been described previously (3). Urinary 17 -ketosteroids were measured by a modification of the Holtorff-Koch technique (9) using dehydroisoandrosterone acetate as the standard. Ketonic separations were carried out as described by Pincus and Pearl$\operatorname{man}(10)$.

Chorionic gonadotropin was administered to the subjects by intramuscular injections, the total daily dosage being divided into two or three portions given six to ten hours apart. After several preliminary studies (7) a standard schedule covering six days was established per-

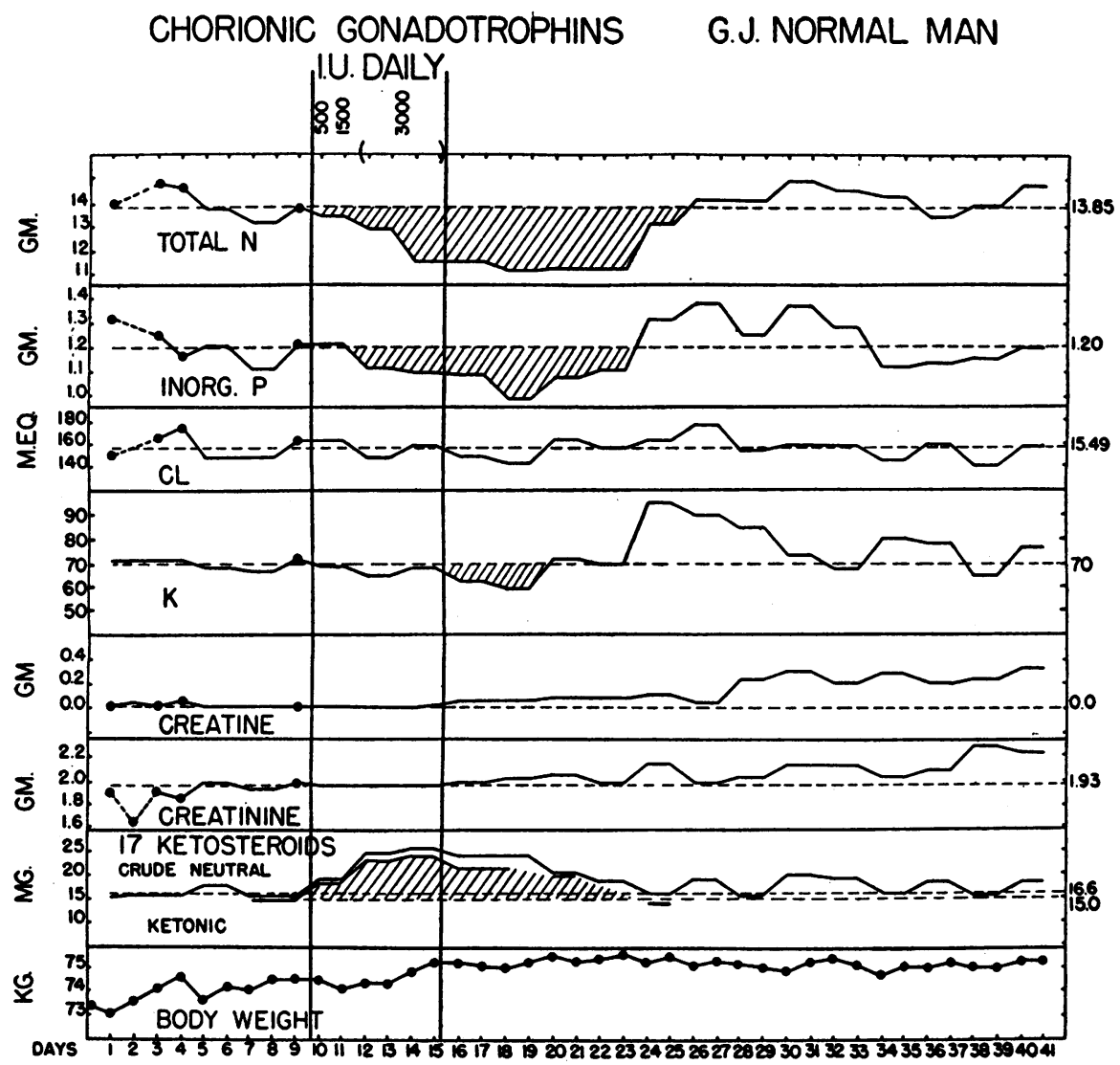

Fig. 1. The Effects of a Standard Course of Chorionic Gonadotropin on Several

Urinary Constituents and on Body Weight of G.J., a Normal Male, Aged 24

The horizontal interrupted lines and the corresponding figures to the right mark pretreatment baselines. Shading indicates significant change during treatment. Creatine, $1.16 \mathrm{gm}$., was fed throughout. Isolated dots mark individual daily determinations; otherwise two day pools provide the information expressed by running lines. 
mitting a comparison of effects from subject to subject. "APL," Ayerst, McKenna and Harrison, was used. The dosage and duration of treatment chosen was sufficient to elicit an unqualified response in normal men without inducing toxic reactions. 14,000 I.U. were distributed as follows: Five hundred I.U. were given in two portions the first day; $1,500 \mathrm{I}$.U., in three injections the second day; and 3,000 I.U., in three doses of 1,000 I.U. each for the last four days. This standard dosage was utilized in four of the six experiments reported here. In T.H. somewhat smaller doses of another preparation ("Follutein," Squibb) were given in a similarly divided fashion (see protocols).

\section{PROTOCOLS}

G.J. (Figure 1) was a 24-year-old sudent whose basal metabolic rate was - 13 (Mayo Foundation Standard); basal calories, 1,590 per day. He was placed on a constant diet consisting of carbohydrate $325 \mathrm{gm}$., protein 99 gm. (nitrogen $15.8 \mathrm{gm}$.), fat $139 \mathrm{gm}$., calories 2,947. Four gm. of salt were added each day. Although he was fed $1.16 \mathrm{gm}$. of creatine each day creatinuria sufficient for study did not develop. The standard six day dosage (see Methods) of chorionic gonadotropin ("APL," Ayerst, McKenna and Harrison) was administered without untoward reaction.

C.A. (Figure 2) was also 24 years old. His basal rate was \pm 0 (Mayo Foundation Standard); basal calories were 1,890 per day. His constant diet included $395 \mathrm{gm}$. carbohydrate, $109 \mathrm{gm}$. protein (nitrogen 17.5 $\mathrm{gm}$.), $153 \mathrm{gm}$. fat and $4 \mathrm{gm}$. of added salt. The caloric intake totaled 3,401 . $1.16 \mathrm{gm}$. of creatine were fed daily. The subsequent creatinuria showed irregularities during the control period that have led us not to chart the data. He received the standard course (see Methods) of chorionic gonadotropin ("APL") without toxic reaction. For personal reasons he was unable to continue the studies after the fourth post-treatment day.

G.M., aged 23, was without significant physical abnormalities. Although he was receiving psychiatric aid he was well able to pursue his studies. His basal metabolic rate was - 1 (Mayo Foundation Standard); basal calories, 1,590 per 24 hours. He was placed on a constant diet of $338 \mathrm{gm}$. carbohydrate, $100 \mathrm{gm}$. protein (nitrogen $16.0 \mathrm{gm}$.) and $145 \mathrm{gm}$. fat. The total caloric value was 3,057 . Three $\mathrm{gm}$. of salt were added to his food, and 1.32 gm. of creatine hydrate were fed daily. The subsequent creatinuria was sufficiently consistent for study.

He received the standard six day dosage ("APL"), and felt well throughout the treatment (Figure 3). Unfortunately the recovery phase was interrupted by an acute non-specific urethritis which extended to the prostate and bladder (noted by broken lines). Treatment with sulfadiazine, penicillin and ultimately streptomycin was required. After recovery from the intercurrent illness and while on the same constant diet the metabolic effects of testosterone propionate were determined. Five mg. daily were administered for eight days followed after a three day gap by $25 \mathrm{mg}$. daily for the same length of time (Figure 4).
T.H. (Figure 5), aged 26, was the oldest subject. His basal metabolic rate was -7 (Mayo Foundation Standard); basal calories, 1,610 per 24 hours. His diet was $372 \mathrm{gm}$. carbohydrate, $85 \mathrm{gm}$. protein (nitrogen $13.6 \mathrm{gm}$.), $105 \mathrm{gm}$. fat, calories 2,773. Two $\mathrm{gm}$. of sodium chloride were added. The administration of chorionic gonadotropin (Squibb's "Follutein") was continued for 12 days at a lower level than the standard regime. A total of 14,500 I.U. was given. The 500 and 1,000 I.U. doses were each administered in two spaced injections daily; at the 1,500 I.U. level three daily injection of 500 units each were given. The sites of repeated injection were rather tender after the first few days, but no erythema or induration appeared. The only general reaction was a very mild fatigue toward the end of the treatment period.

$Y . W$. was a 21-year-old eunuchoid. Growth and development were normal until the time of puberty, when the absence of sexual maturation was noted. Y.W. felt

\section{CHORIONIC GONADOTROPINS C.A. NORMAL MAN}

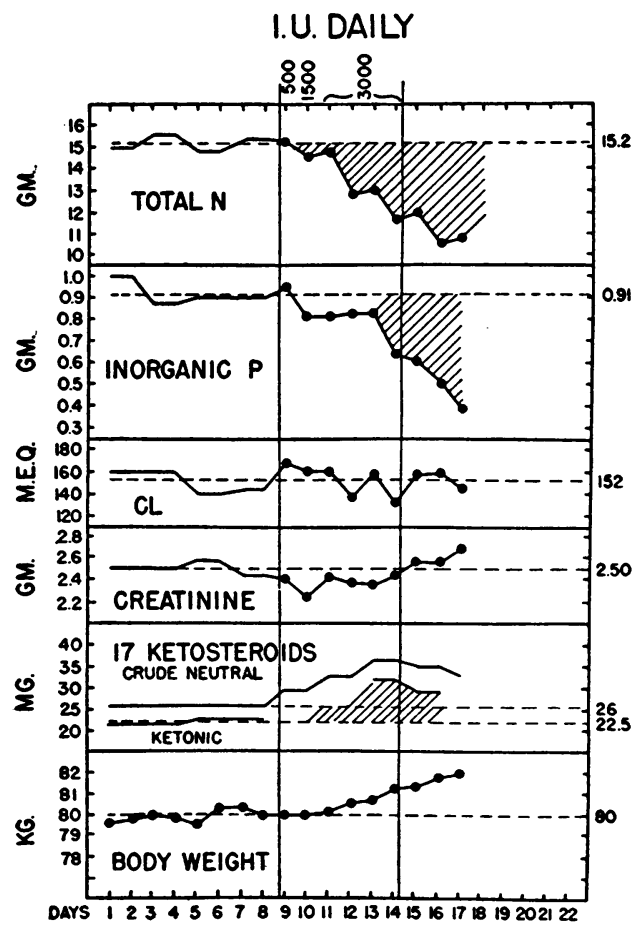

Fig. 2. The Effects of a Standard Course of Chorionic Gonadotropin on Several Urinary ConSTItUents and on Body Weight of C.A., a Normal Male, Aged 24

The horizontal interrupted lines and the corresponding figures to the right mark pre-treatment baselines. Shading indicates significant change during treatment. The isolated dots mark individual daily determinations; otherwise two day pools provide the information expressed by running lines. 
CHORIONIC GONADOTROPINS

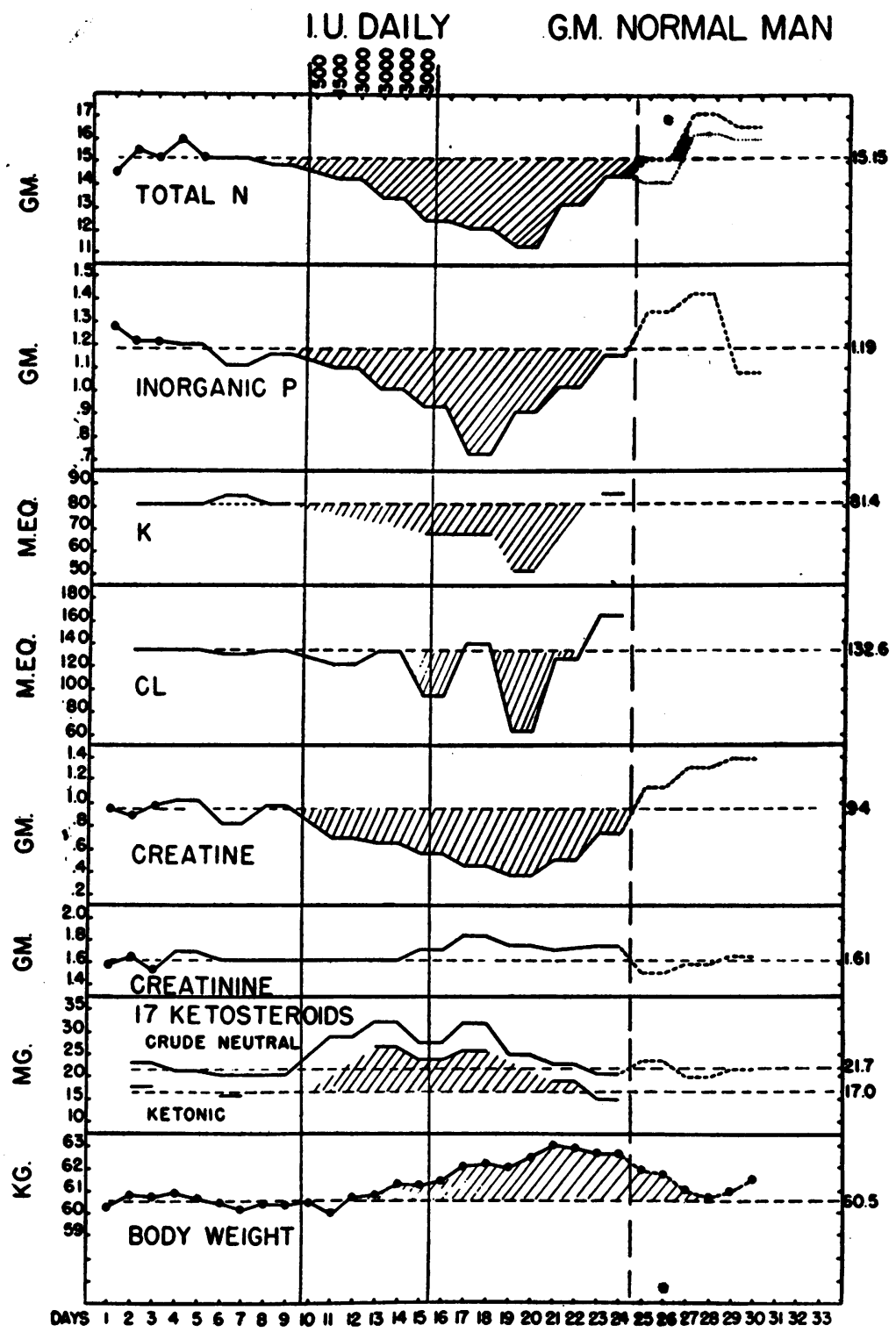

Fig. 3. The Effects of a Standard Course of Chorionic Gonadotropin on Several Urinary Constituents and on Body Weight of G.M., a Normal Male, Aged 23

The horizontal interrupted lines and the corresponding figures to the right mark pre-treatment baselines. Shading indicates significant change during treatment. The interrupted vertical lines after day 24 mark the beginning of an acute non-specific urethritis; antibiotics were started on the starred day. The heavier line for urinary nitrogen gives total nitrogen, the lighter line non-protein nitrogen. The data given after day 24 are subject to this complication and the lines are accordingly dotted. Creatine hydrate, 1.32 gm., was fed daily.

Blood urea nitrogen values before the gonadotropin were 15.4 and 13.7 mg.\%; during and after treatment they declined as follows: day 12, 11.2 mg.\%; day 18, $9.3 \mathrm{mg} . \%$; day $20,9.2 \mathrm{mg} . \%$. On day 28 the value was 13.7 mg.\%. Serum inorganic phosphorus declined from $4.1 \mathrm{mg} . \%$ before treatment to $3.2 \mathrm{mg} . \%$ on day 20 and rose to $4.0 \mathrm{mg} . \%$ on day 28 . 
G.M. NORMAL MAN

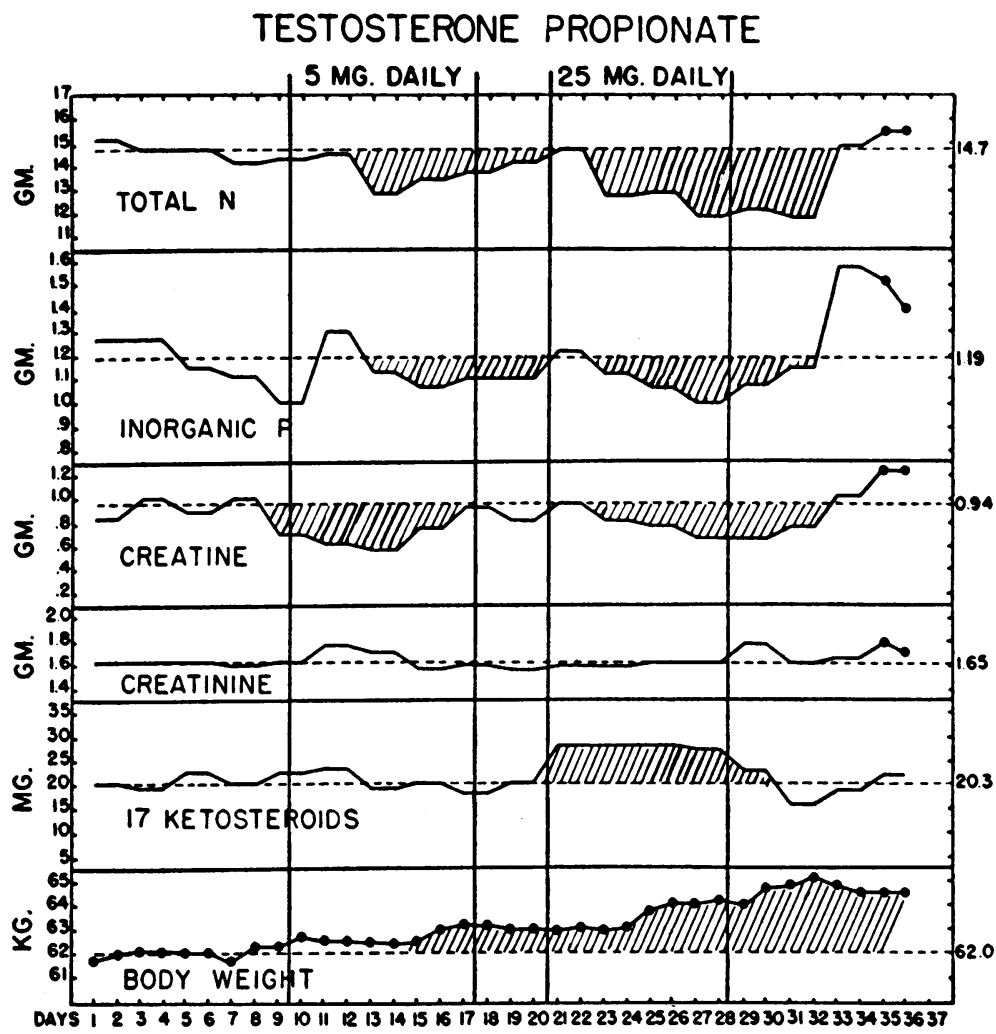

Fig. 4. The Effects of 5 mg. and 25 mg. of Testosterone Propionate Daily on Several Urinary Constituents and Body Weight of G.M., a Normal Male, Aged 23

The horizontal interrupted lines and the corresponding figures to the right mark pre-treatment baselines. Shading indicates significant change during treatment. The ketonic fractions of the 17-ketosteroids were 22.4 and 24.2 mg. per day for two two-day pools, covering days 23-26 above. The baseline ketonic value may be estimated as 17.0 taken from Figure 3. The increment in the ketonic fraction of $17-$ ketosteroids after $25 \mathrm{mg}$. of testosterone propionate daily may be estimated accordingly as $6.4 \mathrm{mg}$. per day, confirming the corresponding increments of $6.2 \mathrm{mg}$. in the total neutral fraction shown above. Creatine hydrate, 1.32 gm., was fed daily.

that throughout his youth his strength and athletic ability were distinctly less than average. For approximately two years prior to seeing us he had received weekly and occasionally bi-weekly injections of $25 \mathrm{mg}$. of testosterone propionate. As a result deepening of the voice, slight enlargement of the phallus and the growth of small amounts of pubic and axillary hair were induced. Except for features related to the hypogonadism, the physical examination was within normal limits. He was $6 \mathrm{ft} .11 / 2$ in. tall with disproportionately long limbs. Facial and body hair was very fine; shaving was not necessary. Axillary hair was sparse, and pubic hair assumed a feminine pattern. The phallus was pre-pubertal, the testicles pea-sized. A small firm prostate about
$3 \mathrm{~cm}$. in diameter was felt. Skeletal musculature was not well developed.

An X-ray of the skull was normal; measurements of the sella turcica were within normal limits. The bone age obtained from $\mathrm{X}$-rays of various long bones was compatible with the chronological age. The basal metabolic rate was -27 (Mayo Foundation Standard); basal calories, 1,500 per day. Urinary 17-ketosteroid excretion was $8.0 \mathrm{mg}$. per 24 hours (crude neutral extract) compared with a normal range in our laboratory of from 12 to $30 \mathrm{mg}$. per day. The ketonic fraction was $5.5 \mathrm{mg}$. per day. Testicular biopsies showed small tubules with thin basement membranes. The tubular cells were chiefly spermatogonia and sustentacular cells. The 


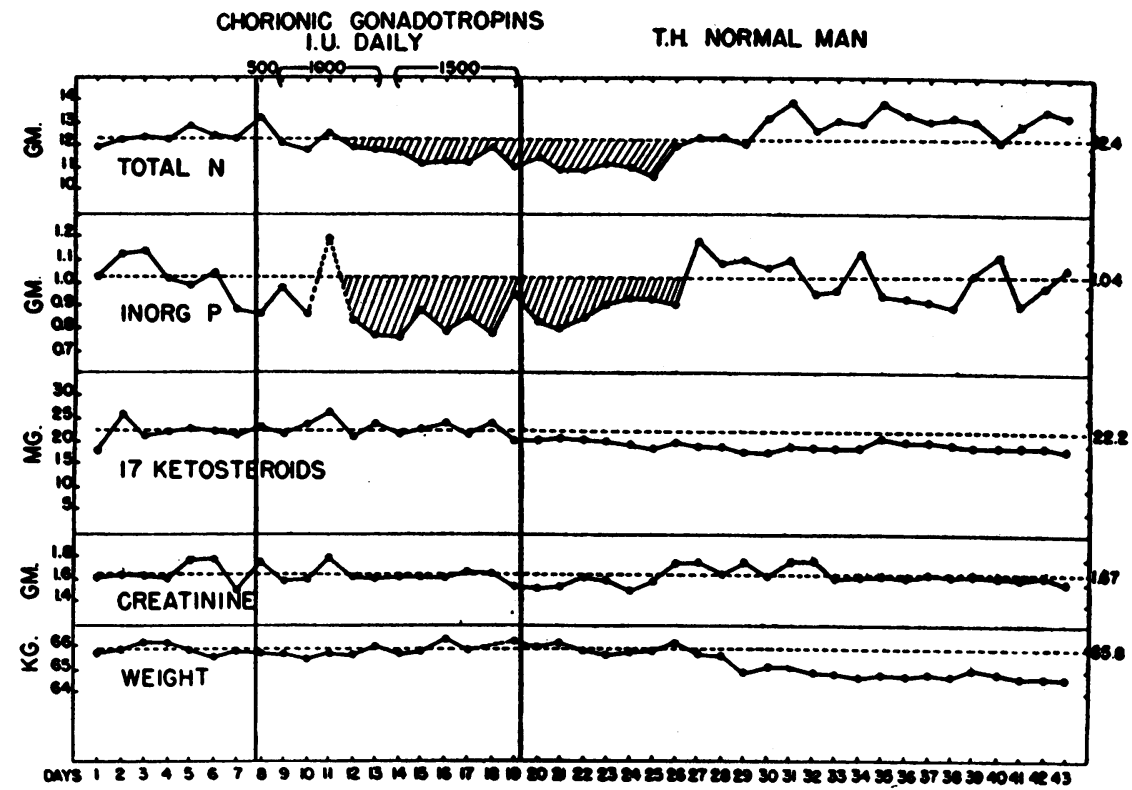

Fig. 5. The Efrects of Chorionic Gonadotropin on Several Urinary Constituents and Body Weight in T.H., a Normal Male, Aged 26

The daily dosage of gonadotropin was somewhat less than that employed in an eventual standard course. The horizontal interrupted lines and the corresponding figures to the right mark pre-treatment baselines. Shading indicates significant change during treatment. 17-Ketosteroids shown are total neutral fractions only.

Y.W. EUNUCHOID

\section{TESTOSTERONE PROPIONATE}

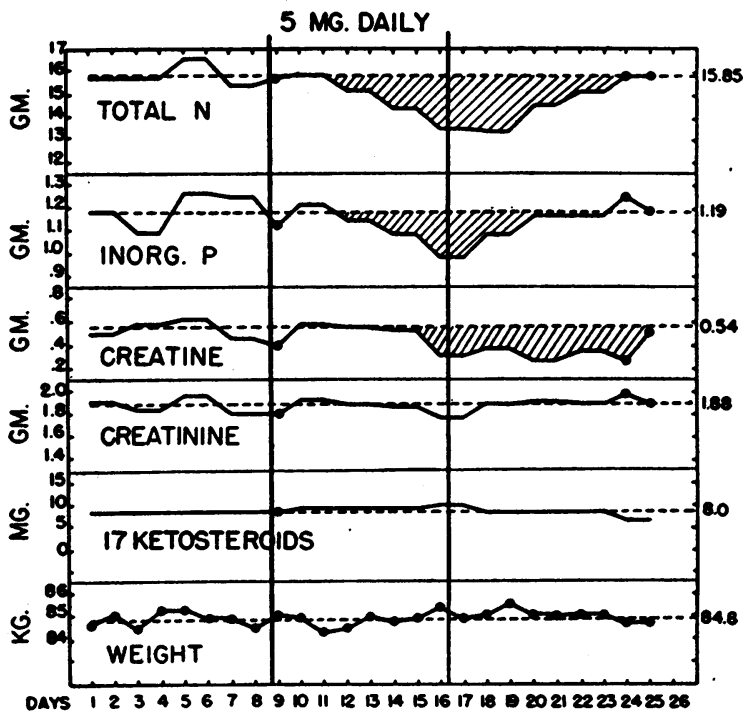

Fig. 6. The Effects of 5 Mg. of Testosterone Propionate Daily on Several Urinary Constituents, INCluding 17-Ketosteroids (Total Neutral), aNd Body WEIGHT OF THE EUNUCHOId Y.W., AGEd 21

The horizontal interrupted lines and the corresponding figures to the right mark pre-treatment baselines. Shading indicates significant change during treatment. Creatine hydrate, $1.32 \mathrm{gm}$., was fed daily. stroma was loose with very few Leydig cells present. No statement as to the functional integrity of these cells could be made from the section.

He was placed on a diet of $335 \mathrm{gm}$. carbohydrate, 97 gm. protein (nitrogen $15.5 \mathrm{gm}$.), $121 \mathrm{gm}$. fat, calories 2,817. Two gm. of sodium chloride were added. Since spontaneous creatinuria was not present he was fed $1.32 \mathrm{gm}$. of creatine hydrate daily with resulting creatinuria. In the first study (detailed results not charted) he was given 12,000 I.U. of chorionic gonadotropins ("APL") in six days. The dosage was 500 I.U. the first day, 1,500 I.U. the second day, 2,000 I.U. daily the third and fourth days, followed by 3,000 I.U. daily the last two days of treatment. Urinary nitrogen, inorganic phosphorus, creatine, creatinine and $17-$ ketosteroids were determined throughout. The only change noted was a slight decline of from 0.3 to $0.6 \mathrm{gm}$. in nitrogen beginning the third and fourth days of treatment. Since the control baseline was not resumed on the discontinuance of treatment the significance of this variation in nitrogen excretion seemed doubtful.

Seventeen days later $5 \mathrm{mg}$. per day of testosterone propionate were administered for eight days (Figure 6). The diet was then changed to $419 \mathrm{gm}$. carbohydrate, 103 gm. protein (nitrogen 15.4), fat $134 \mathrm{gm}$., calories 3,294, and the standard six day course of chorionic gonadotropin (see Methods) was administered (Figure 7). The total of 14,000 I.U. slightly exceeded that given in the first course of the treatment. 
Y.W. EUNUCHOID

CHORIONIC GONADOTROPINS

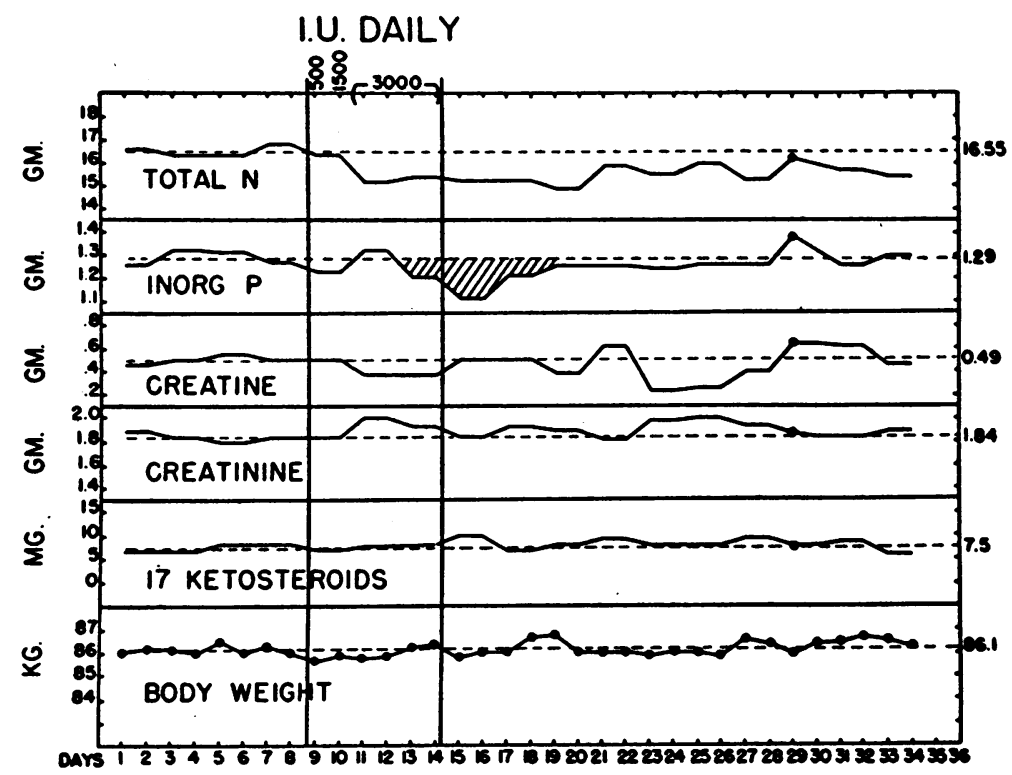

Fig. 7. The Efrects of a Standard Course of Chorionic Gonadotropin on Several Urinary Constituents and on Body Weight of THE Eunuchord Y.W., Aged 21

The dotted lines and the corresponding figures to the right mark pretreatment baselines. Shading indicates significant change during treatment. 17-Ketosteroids given are total neutral fraction only. Creatine hydrate, $1.32 \mathrm{gm}$. , was fed daily.

\section{RESULTS AND DISCUSSION}

The anabolic effects of chorionic gonadotropin in the four normal young men (Figures 1-3, 5) were similar in kind to the effects of testosterone propionate. Studies on G.M. (Figures 3 and 4) illustrate the agreement between the responses to the two agents in the same individual, in conformity with a previous comparison in a boy in early puberty (6). The decline in urinary nitrogen and inorganic phosphorus in patterns characteristic for androgen effect was exhibited uniformly by the four subjects. As with testosterone propionate the concentrations of urea nitrogen in the blood and of inorganic phosphorus in the serum were not elevated and indeed declined somewhat (subscript Figure 3). Creatinuria was reduced in G.M. in whom creatine excretion was sufficiently consistently elevated by creatine feeding to permit a suitable experiment (Figure 3 ). This subject likewise showed a striking depression in urinary potassium excretion while in G.J.
(Figure 1) the effects were less distinct. A decisive reduction in urinary chloride excretion was induced in G.M. (Figure 3) who showed the most conspicuous evidences of salt and water retention by a gain in weight, but not in the other two subjects in which it was determined (G.J., C.A., Figures 1 and 2). Variations in the sensitivity of chloride and potassium excretion have been noted by us in the past in experiments with testosterone propionate so that such inconsistencies are not an occasion for surprise. In general the metabolic expressions of androgen effect were most complete in G.M. in whom the response in nitrogen retention was most intense.

The course of urinary 17-ketosteroid excretion in the three experiments with our standard schedule (Figures 1-3) fits the trend of metabolic events sufficiently well to support the supposition that a hormone yielding urinary 17 -ketosteroids actually mediated the anabolic effects of the gonadotropin. Thus a decisive increase in 17-ketosteroid excretion occurred regularly on days $3-4$ of treat- 
ment, corresponding to the earliest discernible metabolic effects. The metabolic effect with respect to nitrogen retention reached its maximum intensity on the fifth to the tenth days after the start of treatment and lasted until the 13th to the 14th days, enduring as long as eight days after the last stimulating injection. 17-Ketosteroid excretion was vigorous during the height of the metabolic response and remained so for some three days after the last injection, declining toward baseline levels before the recession of the anabolic effect.

The precise composition of the 17-ketosteroid mixture obtained here cannot be ascertained by methods at our disposal. The ketonic fraction was consistently elevated (Figures 1-3). Studies by two of us (R.L.L., K.L.), reported thus far in preliminary form only (8), show that compounds like dehydroisoandrosterone did not participate in the increase of 17 -ketosteroid excretion. In this respect the response is like that to testosterone propionate and unlike that to adrenocorticotropin. In the latter instance compounds like dehydroisoandrosterone in chromogenic capacity form a substantial fraction of the increment. This may be taken as evidence that a non-specific adrenocortical reaction did not contribute to the rise in 17-ketosteroids after chorionic material.

The interstitial cell stimulating properties of chorionic gonadotropin are so well established that it can be fairly assumed that at least part of the anabolic effects noted were actually due to enhanced secretion of testicular androgens. It was possible, however, that the response was mediated in part by some other gland of internal secretion such as the adrenal cortex or that chorionic gonadotropin had some unanticipated direct effect on somatic tissue. The eunchoid Y.W. (protocols, Figure 7), with presumably inactive testes, responded so slightly to the chorionic material, however, that it may be judged that by far the greater part of the anabolic effects described in the normal men were indeed mediated by the testes. All semblance of influences of other origin were not, however, finally excluded. A detailed consideration of these minimal and uncertain changes follows.

The administration of chorionic gonadotropin to Y. W. by our standard schedule (Figure 7) was accompanied by a slight decline in urinary nitrogen which was difficult to interpret because it was not succeeded by a satisfactory return to the control baseline when treatment was stopped. Adventitious changes in metabolism or errors in procedure may contribute to variations of this sort. The most that can be made of this decline in nitrogen, using only the initial baseline excretion for guidance, gives an estimated retention of $16 \mathrm{mg}$. per $\mathrm{kg}$. body weight per day at the time of maximum effect. The true value may well have been much less. However, when $5 \mathrm{mg}$. of testosterone propionate daily were given to this same subject (Figure 6), the usual sensitivity of hypogonad men to androgens was revealed. A thoroughly satisfactory curve of nitrogen excretion permits an estimate of the retention of $28 \mathrm{mg}$. of nitrogen per $\mathrm{kg}$. per day at the time of maximum effect. This corresponds very well to figures of 27,30 and $39 \mathrm{mg}$. retained by three other eunuchoids in previous studies of our own. The effects of the chorionic gonadotropin were accordingly distinctly less than those of $5 \mathrm{mg}$. of testosterone propionate in this regard. Reduction in urinary creatine was clear-cut with the small dose of testosterone propionate (Figure 6) and questionable with the gonadotropin (Figure 7). The sharp rise of urinary 17 -ketosteroids, so characteristic of normal men receiving our standard schedule, was virtually absent in the eunuchoid receiving chorionic material, testifying to the necessity for an intact testis for this reaction to develop. Only the brief but distinct reduction in urinary inorganic phosphorus (Figure 7) spoke clearly for a response of the eunuchoid like that to androgens. This together with the imperfect response in urinary nitrogen described above lead us to believe that some minimal anabolic effects may actually have been induced in Y.W. The previous study with a slightly substandard schedule (see protocols) gave much the same findings in still less degree. Such indistinct and incomplete anabolic effects may have been due to stimulation of residual Leydig cells, to stimulation of some other gland as the adrenal or to direct effect of the trophic hormone on somatic tissues. Our failure thus far to get any clear response in women suggests that the first answer is probably the correct one.

The magnitude of the response to our standard schedule of gonadotropin in the three normal 
young men (Figures 1-3) testifies to the exquisite sensitivity of the testis to suitable stimulation at this time of life. The extent of this response may be estimated both from 17-ketosteroid excretion and from the results of the metabolic studies. Quantitative comparisons with the effects of testosterone propionate are instructive in illustrating the intensity of these processes. They must, however, be made with due reservation since the natural hormone secreted under the influence of chorionic material presumably differs from the injected propionate in its ester form. It may likewise enter the circulation at a rate more favorable for maximal tissue response. Thus while qualitative differences between the natural hormone and testosterone propionate do not appear important, quantitative differences may be, and express themselves in variations in the intensity of the response of the tissues and in the amounts of derived 17ketosteroids excreted in the urine.

Testicular contributions to urinary 17 -ketosteroids may well have been roughly doubled in these normal men by the stimulus of chorionic gonadotropin. The increments in the ketonic fraction at the time of maximum sustained effect were $6.9,8.1$ and $8.5 \mathrm{mg}$. per day in G.J. (Figure 1), C.A. (Figure 2) and G.M. (Figure 3). These constitute increases of $36-50 \%$ above the corresponding initial baseline values of 15.0, 22.5 and $17.0 \mathrm{mg}$. per day. The precise amount of the testicular components of the 17 -ketosteroid mixture of normal young men at this age is uncertain. Little information on young castrates has been published and estimates must be based on the available studies on eunuchoids. Dorfman (11) in reviewing this available information has estimated that eunuchoids usually excrete less than half the total provided by normal men. Inspection of the most extensive series of eunuchoids between the ages of 18 and 29, that of Fraser and his associates (12), supports this approximation. Our own subject, Y.W., who excreted $8 \mathrm{mg}$. of total neutral 17-ketosteroids ( $5.5 \mathrm{mg}$. ketonic fraction) fits such an estimate. Taking one-half of the control values of our normal subjects as a crude estimate of the testicular contribution before treatment, the increments following chorionic gonadotropin appears to represent a doubling of these elements in the urinary steroid mixture. It is of interest that the increment of $8.5 \mathrm{mg}$. in G.M.
(Figure 3) was very close to that of $6.4 \mathrm{mg}$. provided by $20.7 \mathrm{mg}$. of testosterone ( $25 \mathrm{mg}$. of the propionate) daily in the same subject (Figure 4). While this should not be taken literally as meaning that the stimulated testis enhanced its output by some $20 \mathrm{mg}$. or more of testosterone daily the impression given of considerable secretory activity is certainly the correct one.

The anabolic response to the standard schedule of gonadotropin was as intense as that to $25 \mathrm{mg}$. of testosterone propionate in normal young men. Thus the nitrogen retention induced in G.J., C.A., and G.M. was estimated as 33,55 and $60 \mathrm{mg}$. per $\mathrm{kg}$. per day, respectively, at the times of maximum sustained effect. Twenty-five mg. of testosterone propionate daily in normal young men have been recorded as producing a nitrogen retention of 29 $45 \mathrm{mg}$. per $\mathrm{kg}$. per day in five subjects studied ([3, 4], G:M.). Indeed explicit comparison in G.M. (Figures 3 and 4 ) suggests that the effects of the gonadotropin on nitrogen retention $(60 \mathrm{mg}$. per kg. per day) were actually slightly superior to those of the injected steroid ( $45 \mathrm{mg}$. per $\mathrm{kg}$. per day). The effects on the excretion of inorganic phosphorus, creatine and potassium were correspondingly greater. Since it has been difficult to show that $50 \mathrm{mg}$. of testosterone propionate daily have any material advantage over $25 \mathrm{mg}$. in several subjects $(3,13,14)$ it is quite possible that the response to the gonadotropin in G.M. reached or exceeded that obtainable by any amount of extraneous testosterone propionate. Thus from the standpoint of urinary 17 -ketosteroid excretion the stimulated mature testis may well have doubled its output of hormone, with consequent intense anabolic effects that equalled or exceeded those of $25 \mathrm{mg}$. or more of injected testosterone propionate daily.

The study on T.H. (Figure 5) requires consideration at this time since a moderate anabolic effect was induced by a dosage of gonadotropin below our eventual standard without increasing urinary 17-ketosteroid excretion. A somewhat similar result occurred in the work on a short boy in early puberty previously referred to (6). This may be accounted for by the sensitivity of the tissues to amounts of androgen too small to leave certain urinary traces of its presence. Thus $5 \mathbf{m g}$. of testosterone propionate daily may give distinct metabolic effects without increasing 17-ketosteroid 
excretion ([6], Y.W., Figure 6). The 1-2 mg. increment in urinary derivatives expected from these $5 \mathrm{mg}$. is too small to be detected, as spontaneous variations during the control period often exceed such values. Even in the normal male (G.M., Figure 4) $5 \mathrm{mg}$. of injected testosterone propionate had a distinct anabolic effect, although the influence seemed to fade as treatment continued. Compensatory reduction of intrinsic hormone secretion presumably restored the original equilibrium in time. The accompanying variations in 17-ketosteroid excretion were not enough to be surely significant. All of this makes clear enough that it is quite possible for variations in testicular secretion to exert definitive metabolic influences without evoking representation of the process through measurable variations in urinary excretion of 17 -ketosteroids.

An alternative situation is also conceivable. If peripheral sensitivity to secreted androgens should become limited for one reason or another, 17-ketosteroid excretion might rise clearly without the usual expressions of anabolic effect. This may have occurred in one individual referred to in our preliminary note on this subject (7). Here the rise in 17-ketosteroid excretion was quite sharp while the anabolic effect although distinct was not great. While this seemed due to a reaction to toxic contaminants of the gonadotropin the explanation just mentioned is a possibility. Thus variations in the relationships between anabolic effects of the testis hormone and the urinary excretion of the derivatives of that hormone may be expected under certain circumstances.

The foregoing experimental material demonstrates that the testes during the early years of adult life are exquisitely sensitive to stimulation above and beyond that provided at the time by the pituitary body. The movement of the youthful organism toward nitrogen equilibrium with the assumption of adult life appears divided into at least two phases as far as the testis is concerned. The response of the non-genital tissues to that amount of androgen required for the maintenance of the genital accessories and other dependent structures must be limited in as yet obscure ways so that such maintenance levels of secretion no longer produce progressive nitrogen retention. These tissues still remain sensitive, however, to larger amounts of the androgen. The testes do not usually secrete these larger amounts because the governing pituitary secretion is delivered to them in moderated fashion, well below the testes' ceiling of reactivity. The testes can and do react sharply above this level and in so doing exert profound anabolic effects on the organism. Such sensitive testes are potential contributors to the regulation of variations in protein metabolism and may be so utilized. Thus increments in androgen production could support anabolic processes and decrements favor catabolic processes. The current concept of a constant level of testicular secretion for a given time in life may be correct but it is not necessarily so.

Any actual demonstration of such testicular participation in the regulation of variations in protein metabolism will be difficult. There is serious need for a more delicate and more explicit measurement of androgen production. The elaborate detail now required is illustrated by the present report. Variations in 17-ketosteroid excretion are not sensitive enough, as metabolic effects of testicular origin may occur without distinct changes in steroid excretion. Manifest variations in 17-ketosteroid excretion may be quite ambiguous. We have already puzzled over the meaning of the reduction of urinary 17-ketosteroids during starvation (15) and remained uncertain as to whether testicular, adrenal or hepatic mechanisms were affected. Until more satisfactory indicators of testicular function can be correlated with variations in protein metabolism this question will continue as open as it now stands.

The procedure for determining the reactivity of the testes finally arrived at here seems suitable as a standard method, and may be extended to several ages and to disease states where the matter may be of interest. Complicating direct tissue effects or adrenal response do not appear to be serious. Extension of these studies to the female is in progress.

\section{SUM MARY}

1. Chorionic gonadotropin administered to normal young adult males induced anabolic effects similar to those of testosterone propionate, accompanied by increased excretion of urinary 17 ketosteroids.

2. The effects in a eunuchoid with inactive testes were indistinct and incomplete. Such anabolic ef- 
fects as occurred were decidedly less than those of $5 \mathrm{mg}$. of testosterone propionate daily.

3. The influences of chorionic gonadotropin were exerted chiefly through the testes. Minimal influences of other origin were not completely excluded.

4. Testicular contributions to urinary 17 -ketosteroid excretion were approximately doubled by the gonadotropin, and the intensity of the ensuing anabolic effects equalled or exceeded those of 25 $\mathrm{mg}$. of testosterone propionate daily.

5. In the early phases of adult life the testes may be considered sensitive to pituitary stimuli above and beyond the level required for maintenance. The somatic tissues are similarly sensitive to androgens. The testes do not secrete sufficient androgens to evoke this maximal tissue response because pituitary stimuli acting upon them are moderated and restrained in their intensity.

6. Such sensitive testes are potential contributors to the regulation of variations in protein metabolism during adult life through these anabolic effects of secreted androgens. There is, however, no actual demonstration of such control as yet.

7. A standard procedure for ascertaining the reactivity of the testes under various conditions is suggested.

\section{ACKNOWLEDGMENTS}

We are indebted to the personnel of the metabolism unit under Miss Blanche Parish, to Dr. Irene Sandiford and her assistants in the Basal Metabolism Laboratory and to several chemical technicians including especially Mrs. Judith Gold for their invaluable aid in the prosecution of this work.

\section{BIBLIOGRAPHY}

1. Kenyon, A. T., Knowlton, K., and Sandiford, I., The anabolic effects of the androgens and somatic growth in man. Ann. Int. Med., 1944, 20, 632.

2. Kochakian, C. D., The protein anabolic effects of steroid hormones, in: Vitamins and Hormones; Advances in research and applications (ed. by Harris, R. S., and Thimann, K. V.) Academic Press, Inc., New York, 1946, Vol. IV, p. 255.

3. Kenyon, A. T., Knowlton, K., Sandiford, I., Koch, F. C., and Lotwin, G., A comparative study of the metabolic effects of testosterone propionate in normal men and women and in eunuchoidism. Endocrinology, 1940, 26, 26.

4. Bassett, S. H., Keutmann, E. H., and Kochakian, C. D., Comparative effects of methyl-androstanediol orally and testosterone propionate intramuscularly. Tr. Sixth Conf. Metabolic Aspects Convalescence. Josiah Macy, Jr. Foundation, New York, 1944, p. 75.

5. Kenyon, A. T., Knowlton, K., Lotwin, G., and Sandiford, I., Metabolic response of aged men to testosterone propionate. J. Clin. Endocrinol., 1942, 2, 690 .

6. Kenyon, A. T., Knowlton, K., Lotwin, G., Munson, P. L., Johnston, C. D., and Koch, F. C., Comparison of metabolic effects of testosterone propionate with those of chorionic gonadotropin. J. Clin. Endocrinol., 1942, 2, 685.

7. Kenyon, A. T., Knowlton, K., and Landau, R. L., Metabolic effects of chorionic gonadotrophin. $\mathrm{Tr}$. 16th Conf. Metabolic Aspects Convalescence. Josiah Macy, Jr. Foundation, New York, 1947, p. 38.

8. Landau, R. L., and Lugibihl, K., The estimation of dehydroisoandrosterone and related compounds in human urine by a modification of the Pettenkoffer reaction. J. Clin. Endocrinol., 1948, 8, 617.

9. Landau, R. L., Diagnostic significance and laboratory methods in determination of the 17-ketosteroids. Am. J. Clin. Path., 1949, 19, 424.

10. Pincus, G., and Pearlman, W., Fractionation of neutral urinary steroids. Endocrinology, 1941, 29, 413.

11. Dorfman, R. J., Biochemistry of the androgens, in: The Hormones (edited by Pincus, G., and Thimann, K. V.). Academic Press, Inc., New York, 1948, Vol. I ; p. 506.

12. Fraser, R. W., Forbes, A. P., Albright, F., Sulkowitch, H., and Reifenstein, E. C., Jr., Colorimetric assay of 17-ketosteroids in urine; survey of the use of this test in endocrine investigation, diagnosis and therapy. J. Clin. Endocrinol., 1941, 1, 234.

13. Sandiford, I., Knowlton, K., and Kenyon, A. T., Basal heat production in hypogonadism in men and its increase by protracted treatment with testosterone propionate. J. Clin. Endocrinol., 1941, 1, 931.

14. Kenyon, A. T., Knowlton, K., and Landau, R. L., Anabolic effects of testosterone propionate and related compounds in patients with debility. $\mathrm{Tr}$. Third Conf. Metabolic Aspects Convalescence. Josiah Macy, Jr. Foundation, New York, 1943, p. 128.

15. Landau, R. L., Knowlton, K., Anderson, D., Brandt, M. B., and Kenyon, A. T., The effects of starvation on urinary 17 -ketosteroid excretion. J. Clin. Endocrinol., 1948, 8, 133. 